\title{
The pathways to psychiatric care: a cross-cultural study
}

\author{
R. GATER, ${ }^{1}$ B. DE ALMEIDA E SOUSA, G. BARRIENTOS, J. CARAVEO, \\ C. R. CHANDRASHEKAR, M. DHADPHALE, D. GOLDBERG, A. H. AL KATHIRI, \\ M. MUBBASHAR, K. SILHAN, D. THONG, F. TORRES-GONZALES \\ AND N. SARTORIUS
}

\begin{abstract}
From the Mental Health Division, World Health Organization, Geneva and the Mental Illness Research Unit, University of Manchester
\end{abstract}

SYNOPSIS This paper describes the referral pathways taken by 1554 patients newly referred to the mental health services in 11 countries, and documents factors associated with delays in referral. The pathways in centres relatively well provided with psychiatric staff were dominated by general practitioners and to a lesser extent hospital doctors: the relatively less well resourced centres showed a variety of pathways with native healers often playing an important part. Delays were remarkably short in all centres regardless of psychiatric resources, but in some centres we found longer delays on pathways involving native healers. Somatic problems were a common presentation in all centres, and in some centres there was a tendency for patients presenting with somatic problems to have longer delays than those with symptoms of depression or anxiety. The implications of these findings are discussed in the context of an ongoing programme of WHO research activities aimed at improving the quality of mental illness care available in community settings.

\section{INTRODUCTION}

This paper describes the results of a study coordinated by the World Health Organization and carried out in collaboration with centres in Cuba, Czechoslovakia, India, Indonesia, Kenya, Mexico, Portugal, Pakistan, People's Democratic Republic of Yemen, Spain and the United Kingdom. This paper reports the method and results of the study as a whole: further papers from individual centres will discuss the results found in their own countries from a local perspective. $^{2}$

The pathways which patients take to reach mental health care have rarely been examined in a systematic way. The model put forward by Goldberg \& Huxley (1980) assumed that most patients start by consulting their general prac-

\footnotetext{
'Address for correspondence: Dr R. Gater, University of Manchester, Department of Psychiatry, Withington Hospital, West Didsbury, Manchester M20 8LR.

${ }^{2}$ Further details about the conduct of this work can be obtained from the centres listed or from the WHO in Geneva at the following address: Division of Mental Health, World Health Organization, 1211 Geneva 27, Switzerland.
}

titioner, but it was appreciated that other pathways may be used. The pathways which patients take are likely to be influenced by conventions governing referral, by relationships which exist between mental health services and other sources of help and by the availability/ accessibility of mental health and other helping agencies. It is not known whether delays which occur along the pathways are much affected by the type of pathway, or how much variation there is between countries in the complexity of such pathways.

In 1988, the World Health Organization launched a new programme aimed at improving the quality of mental illness care available in community settings. This programme was designed taking into account previous WHO studies and programmes in this area and the considerable amount of new knowledge about these matters which became available recently. Earlier WHO work demonstrated, for example, that psychological symptoms are a frequent cause for contact with health services and that general health staff can be relatively quickly 
trained to deal with these adequately (Harding et al. 1980; Sartorius \& Harding, 1983). Other WHO work also showed that technology necessary for inclusion of mental health care into general health care is adequate and that countries were willing to enrich their health care by adding this component to their services. It therefore became important to learn more about the pathways of patients with psychiatric problems so as to be able to train health staff and make other arrangements necessary to provide appropriate help as soon as possible after the beginning of patients' contact with services.

It was decided to start this exploration by charting the pathways of patients who reached psychiatric services and this paper reports the result of this study. Further studies will now be undertaken using the methods and experience obtained in this investigation to obtain similar information in other countries and to study pathways of patients reaching other types of services, e.g. general health care out-patient clinics.

The present study reports on a complete set of referrals into mental health care in 11 countries chosen to represent a wide variety of health systems. Thus some centres deliver their care from a number of local community clinics, while others are based in a single central mental hospital. Some allow direct referrals from the community while others allow very few. Some centres have developed relationships with native healers while others have not. Finally, some centres are well supplied with psychiatrists while others have very few.

We are therefore able to study the effects of various levels of provision of service on the delays which occur in seeking care, as well as to document the relationship between delays on the pathway to care and both clinical and demographic factors in a wide range of settings.

\section{METHOD}

For one calendar month all patients newly referred to the mental health services at each participating centre were interviewed using a specially prepared Encounter Form. Every patient who had not received psychiatric care in the previous year was included. The Encounter Form, which takes between five and ten minutes to complete, was filled out by the mental health professional who first saw the patient during their initial interview. In one centre, Manchester, the Encounter Forms were completed by research assistants who interviewed the patient immediately before or after their first interview with the mental health professional. An instruction manual was supplied to each mental health professional giving guidelines on how the Encounter Form should be completed.

The Encounter Form was used to gather systematic information about the sources of care used by patients before seeing the mental health professional. The profession of each previous carer was recorded with the length of time since the patient was first seen, the source of referral, the main problem presented, the main treatment offered and the duration of the patient's journey to see the carer. In addition the ICD-10 diagnosis made by the mental health professional was recorded along with the type of facility in which the first interview took place, the total duration of symptoms and basic demographic data including age, sex, marital status, occupational status, social position and area of residence. The Encounter Form was translated locally for use in Czechoslovakia (Czech), India (Kannada), Indonesia (Bahasa Indonesia), Mexico (Spanish), Portugal (French), Pakistan (Urdu) and Spain (Spanish).

The routes taken by individual patients have been brought together to produce a 'Pathways Diagram' for each centre showing the referral paths taken by patients in the course of seeking care for their problems. The percentage of patients taking each step on the pathways have been mapped onto the pathways diagram and the delays occurring at each step have been compared. Delays have also been compared for different diagnostic groups, presenting problems and duration of the journey to the carer. Statistical analysis comparing delays was carried out using the Statistical Package for the Social Sciences (SPSS, 1986).

In order to estimate the number of psychiatrists per million of the population at risk, a correction was applied to the number of psychiatrists based at each centre according to the proportion of patients they saw from inside and outside their catchment area. The corrected number of local psychiatrists was then divided by the size of the population from the catchment area. These estimates are shown in Table 1 
which is arranged in descending order of psychiatrists per million at risk. This order is continued in all the subsequent tables.

\section{Participating centres}

Eleven centres have completed the first stage of the project. The centres will be presented in rank order, starting with the centre with the most psychiatrists per million at risk (see Table 1), and ending with that with the fewest. Each centre is briefly described in four sections: (i) general description of the catchment area; (ii) type of service offered to new patients; (iii) other sources of care available to people with psychological disorder (e.g. religious healers or voluntary agencies); (iv) special circumstances (if any) pertinent to the pathways to psychiatric care.

The centre in Granada, Spain is in a mixed area with roughly one half of the patients from urban areas and the remainder split between semi-urban and rural areas. Most patients are seen in local community clinics. There is a wide variety of potential sources of care within the community.

The centre in Manchester, England serves a residential area of a large industrial city including both privately owned properties and a very large council estate of rented properties. The service is based in a large hospital where most patients are seen either in the out-patient clinic or on the medical wards. In addition, there are a smaller number of domiciliary visits and community clinics. Within the city are a number of government funded, charitable and voluntary agencies offering various types of support to people with psychological distress.

The centre in Havana, Cuba is located in a residential area in the south-east of the city. Most of the residents in the area are skilled or semi-skilled workers, and there is virtually no unemployment. New psychiatric patients are looked after in psychiatric clinics in the community, and in the emergency unit of the psychiatric department at the general hospital which covers the community. No care for psychiatric patients is provided by traditional healers or faith-healers.

The study area in Setubal, Portugal, is a mixed rural and urban area with most residents involved in rural work. The mental health services are offered mainly through psychiatric clinics in the community. In the rural areas there are some native healers who are used secretly, usually when the medical services fail or when strange symptoms are presented which are understood in terms of sorcery. There is no liaison between the mental health services and the native healers.

Benesov and Kromeriz are two sites in the Czechoslovakian study area that have pooled their data. They are both mixed areas with some agricultural, some forestry and some small-town industrial areas within them. There is no unemployment. Most of the residents own their family houses, about one quarter rent their dwellings, and about $5 \%$ are owned by cooperatives. The majority of patients make their first contact with the psychiatric services through community clinics, and a small proportion are seen at the mental hospital in Kromeriz.

The centre in Mexico City serves part of the city with a mixture of social classes represented, though the residents attending the service studied are mainly those with limited resources. The mental health service is delivered through general medical clinics in community settings. A large part of the data from Mexico City is based on the work of a special children's clinic. There are some spiritualist groups in Mexico City, but members of these groups refuse other treatment and do not usually come in contact with the mental health services.

The catchment area of the centre in Nairobi, Kenya includes both urban areas and peri-urban shanty townships. About half the workforce are skilled or semi-skilled, $30 \%$ are casual manual labourers and between 15 and $25 \%$ are unemployed. The younger members of the large extended families in Kenya are highly mobile and flood Nairobi in search of jobs. The mental health services are well organized by third world standards, and are based at a mental hospital and a large teaching hospital. Native healers are active in the community but have no official status and little is known about their activities. The mental health professionals have not developed any special relationship with them. Almost three-quarters of Kenyan psychiatrists are based in Nairobi and some patients travel for several days from their homes to find treatment there.

The centre in Aden, People's Democratic Republic of Yemen, serves a large mixed area; 
one-third urban, two-thirds rural. Most residents own their own houses, some rent from the government. The service is based at a central mental hospital which is several hundred kilometres from the homes of some patients. Local people often seek care from local healers, but these healers are not recognized in law and no special relationship between them and the mental health services has been fostered.

Ujung Pandang in Indonesia serves mainland Sulawesi and several groups of nearby islands. Most people are employed in farming or fishing. The mental health service is based in a mental hospital situated in the capital of Sulawesi Ujung Pandang. Traditional healers play an important role in the community and there are plans to begin working with them in therapeutic work with in-patients. People travelling in from the island of Selayar can only make the trips in certain months and even then are faced with a trip of several hours to the ferry, a two-hour ferry ride, then a four-hour journey from the ferry up to the hospital.

The centre in Bangalore, India serves a rural village area 20 to 50 kilometres from Bangalore City. The local people are mainly unskilled, working in agriculture or stone cutting, and employment for most is seasonal or irregular. Since 1975 a Community Mental Health Unit has been developed with four local clinics and a programme to increase the awareness of health workers in primary care to mental health problems. This contrasts with the situation in many other rural parts of India where patients have to travel longer distances to the Mental Hospital or Department of Psychiatry. Even so, patients find it difficult to travel up to 10 to 20 kilometres to seek help from the psychiatric clinics because of bad roads, no transport facilities, poverty and lack of manpower to accompany patients who are unable to make the journey alone. Native healers are popular and enjoy a good status: ten have been approached in an effort to educate them in the recognition and referral of neuro-psychiatric cases.

In Rawalpindi, Pakistan the catchment area includes a population of over 4 million, in an area of 5000 square miles with poor communications and poor housing. Most people are unskilled and in the rural areas live and work in an agricultural economy. The mental health service in Rawalpindi has pioneered new ways of delivering community based rural mental health care and has actively involved faith healers; training them in the recognition of common mental disorders and method of referral. There are high rates of internal and external migration. Rawalpindi is an important site in the trafficking of psychoactive drugs from Afghanistan. Such drugs are readily available in the city and the incidence of drug related problems is high.

\section{RESULTS}

The distribution of patients seen at each centre by sex, age and the percentage of single patients is shown in Table 1. The marked female preponderance in the European centres and Havana is reversed in four of the centres in the developing world. The older mean age found in the European centres and Havana is largely accounted for by the presence of an appreciable proportion (up to one-fifth) of patients over the age of 65 in these centres, whereas this group accounted for $3 \%$ or less of the patients seen elsewhere. No children were seen at BenesovKromeriz, Havana or Ujung Pandang. The percentage of single patients is highest in the centres in the developing world.

\section{Pathways to care}

The pattern we found most often was found in the four European centres and Havana in Cuba. It can be seen from Table 1 that these centres are those with the most psychiatrists per million population. This pattern (shown in Fig. 1) is dominated by general practitioners and hospital doctors. Most patients follow a route directly from the community to their general practitioners and straight on to the psychiatric services. Like the subsequent pathways diagrams, Fig. 1 is heavily simplified to include only carers involved in the pathways of more than $1 \%$ of patients. At three centres there were a wide variety of other carers like social workers, voluntary agencies, nurses, and the police, but they appeared in only a small minority of patients. These centres tend to be well-supplied with both psychiatrists and general practitioners, and tend not to have many direct referrals.

Typical patients in Aden (see Fig. 2) and Nairobi (see Fig. 3) also follow a medical pathway. In Aden this is mainly through general 
Table 1. Centres arranged in descending order of psychiatrists per million at risk, showing raw data, rates and demographic characteristics of new patients

\begin{tabular}{|c|c|c|c|c|c|}
\hline \multirow[b]{2}{*}{ Centre } & \multirow[b]{2}{*}{$\begin{array}{l}\text { Number of } \\
\text { returns } \\
\text { in month }\end{array}$} & \multirow[b]{2}{*}{$\begin{array}{l}\text { Psychia } \\
\text { trists/ } \\
\text { million }\end{array}$} & \multicolumn{3}{|c|}{ New patients seen } \\
\hline & & & $\begin{array}{l}\text { Sex } \\
\text { ratio } \\
\text { F:M }\end{array}$ & $\begin{array}{c}\text { Mean } \\
\text { age }\end{array}$ & $\begin{array}{c}\text { Per cent } \\
\text { single }\end{array}$ \\
\hline Granada & 243 & 62 & 1.4 & 38 & 42 \\
\hline Manchester & 250 & 60 & 1.3 & 42 & 34 \\
\hline Havana & 96 & $56^{*}$ & 1.9 & 41 & 22 \\
\hline Setubal & 253 & 40 & 1.4 & 41 & 32 \\
\hline Benesov-Kromeriz & 60 & 37 & $1 \cdot 3$ & 49 & 15 \\
\hline Mexico City & 141 & 36 & $1 \cdot 0$ & 25 & 59 \\
\hline Nairobi & 143 & 12 & $0 \cdot 6$ & 30 & 50 \\
\hline Aden & 126 & 11 & 0.5 & 27 & 50 \\
\hline Ujung Pandang & 68 & 4 & 0.6 & 33 & 43 \\
\hline Bangalore & 85 & 3 & $1 \cdot 1$ & 21 & 58 \\
\hline Rawalpindi & 89 & 2 & 0.4 & 31 & 46 \\
\hline
\end{tabular}

* Rates in Havana are overestimates as base population used in calculation did not include the under 15-year-olds.

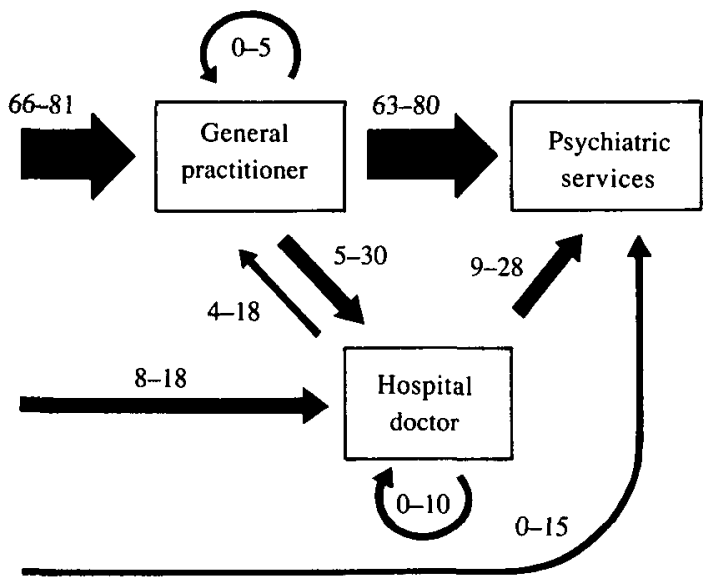

FIG. 1. Main pathways found in Manchester, Setubal, Granada, Benesov-Kromeriz and Havana.

practitioners $(81 \%)$ in contrast to Nairobi where most referrals are from hospital based doctors $(72 \%)$. Thus, the pathways in seven of the centres are dominated by medical sources of referral. The pattern in Mexico (see Fig. 4) is similar to that found in the European centres but with a more substantial group of direct referrals from the community $(24 \%)$.

The remaining patterns have native healers as important parts of the referral pathway. In Rawalpindi and Bangalore the medically based services still feature in over half the patients but the proportion of people coming via their primary care physicians is very much lower than in the earlier patterns (see Fig. 5). As in Mexico, there are substantial numbers of direct referrals,

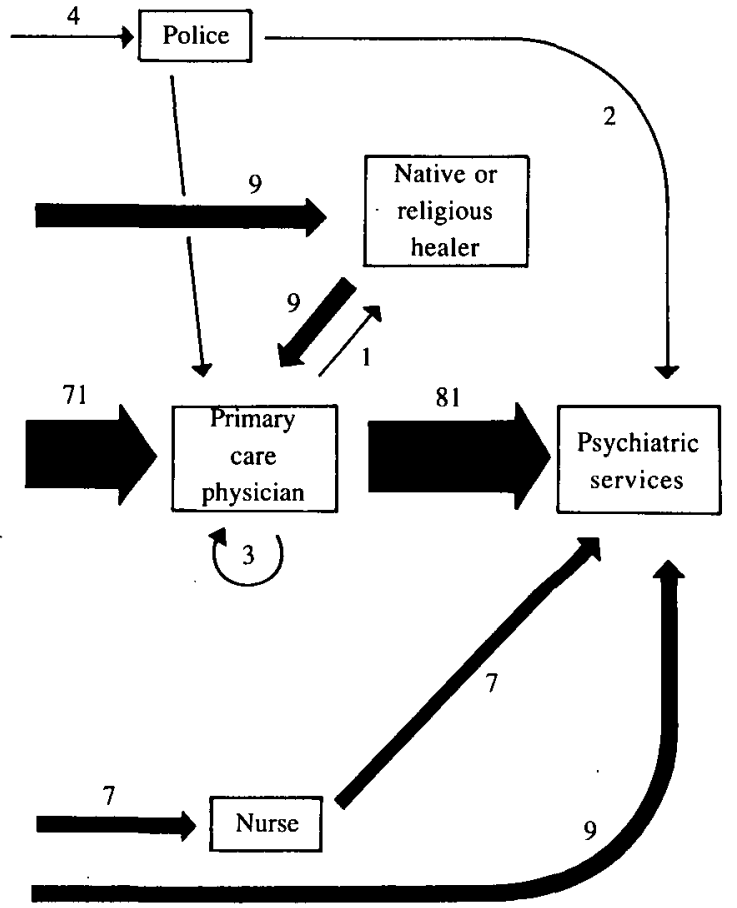

FIg. 2. Pathways found in Aden.

but native healers also refer many patients to the service. Sometimes such patients are referred directly, but some come via a primary care physician.

The final pathway diagram is found in Ujung Pandang (see Fig. 6). This is unique in the study because it is the only centre where the majority of patients report that they do not come via 


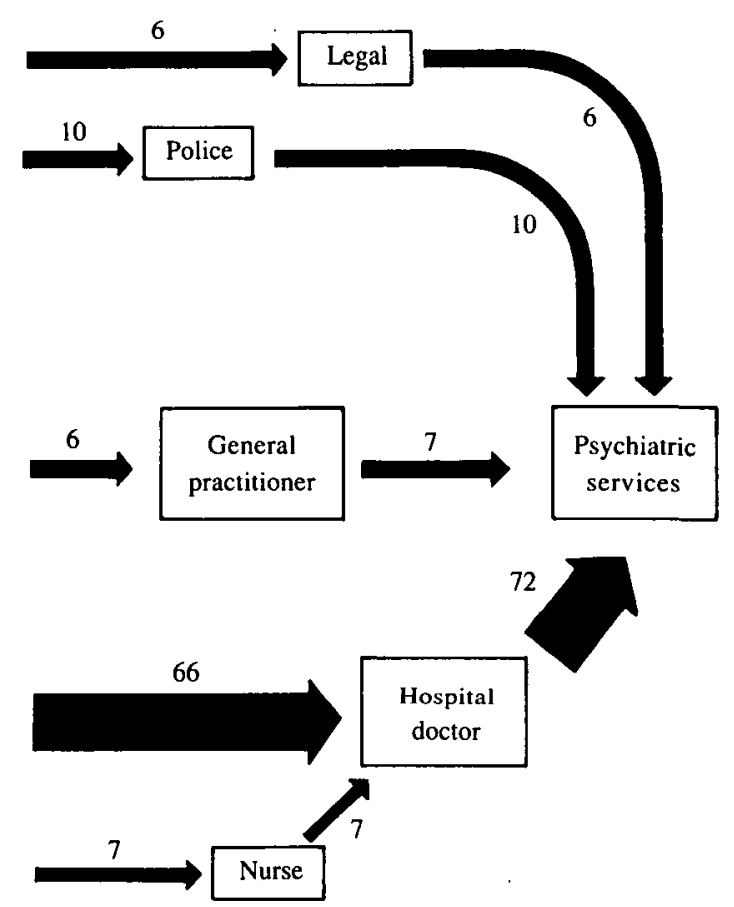

FIG. 3. Pathways found in Nairobi.
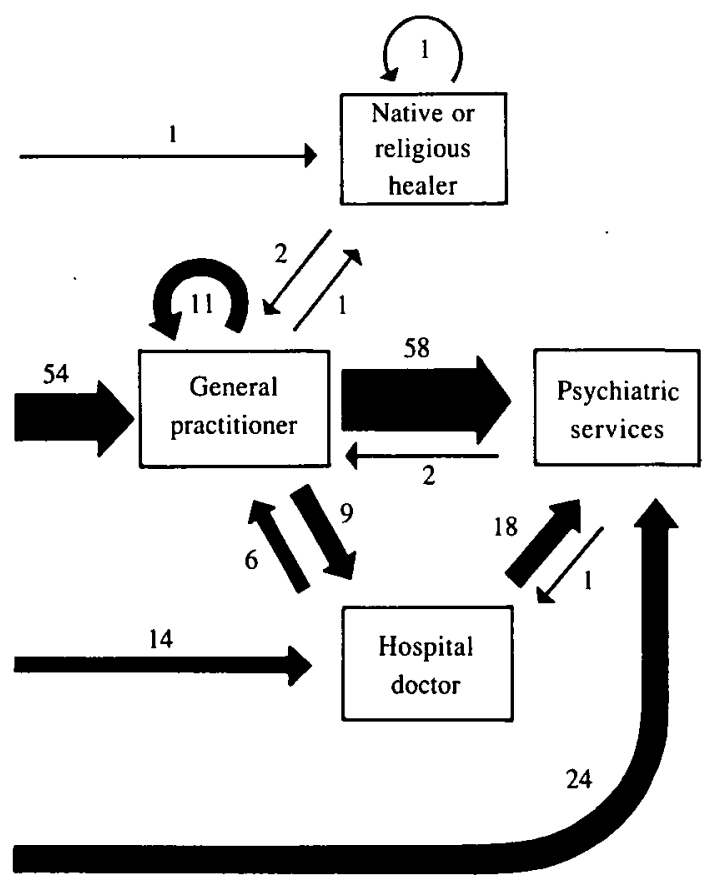

FIg. 4. Pathways found in Mexico City.

doctors. Instead the main previous source of care is the native or religious healer, with most of the remainder coming through the primary

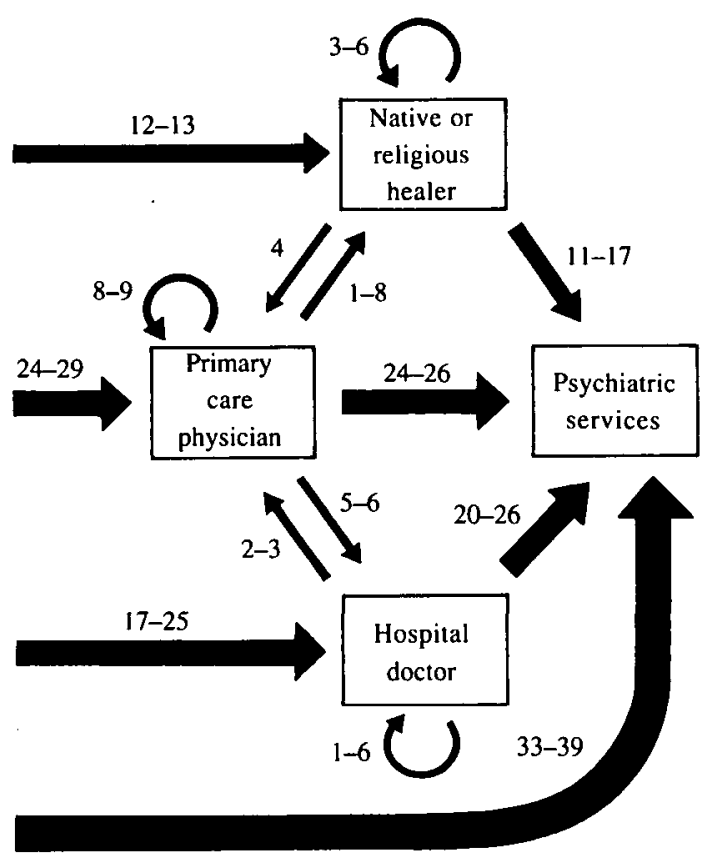

FIG. 5. Pathways found in Rawalpindi and Bangalore.

care physician or by direct access. This diagram also has another feature which although present on some of the other diagrams is a more common occurrence in Ujung Pandang: the recursive path. Twenty per cent of patients went to see two or more different native healers on their pathways.

Virtually all the patients seen by the mental health services in every centre received a psychiatric diagnosis. Overall less then $2 \%$ were diagnosed as 'not ill' and in no centre did the percentage of 'not ill' rise above $4 \%$. The diagnostic breakdown of patients seen in each centre showed some variation according to the organization of services or special problems. For example, the service studied in Mexico City included a child psychiatry unit resulting in a high proportion of patients with disorders of childhood or development. In Bangalore over half the patients seen were epileptic, and in Rawalpindi $30 \%$ had problems of substance abuse.

\section{Delays along the pathway to care}

We are presenting median values as the best representation of delays because the distribution is heavily skewed. For the entire data set the modal delay between first seeking care and 


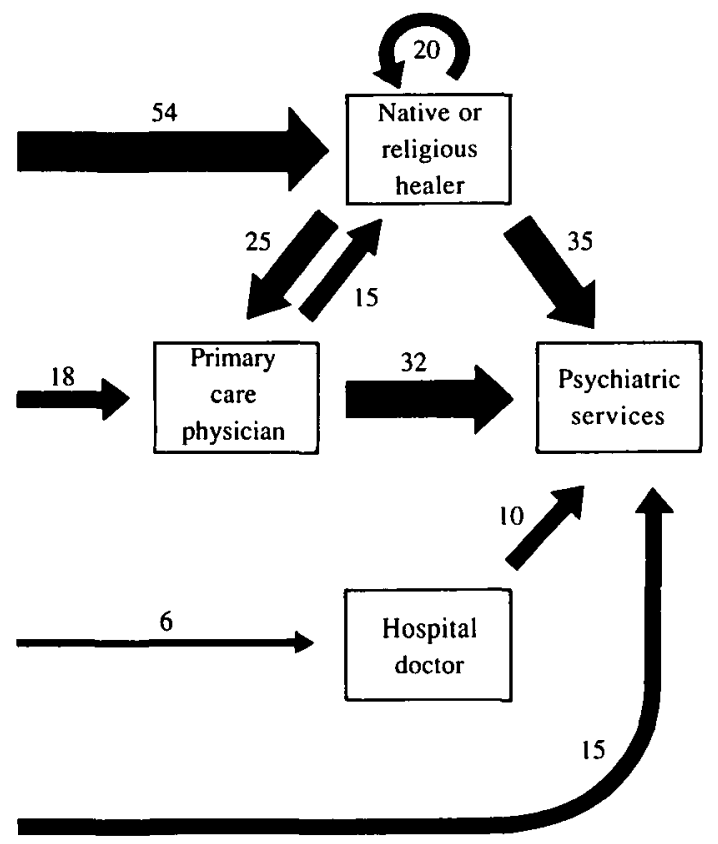

FIG. 6. Pathways found in Ujung Pandang.

seeing a mental health professional is less than one week, and $50 \%$ of patients have a delay of less than two weeks. However, the distribution has a long tail with progressively smaller numbers of patients having longer delays, and indeed a very small number of patients are delayed between 5 and 20 years - so that the mean delay becomes inflated to 22 weeks. We have therefore decided that median values give a fairer picture than means. So median values are used in all the tables that follow.

\section{(i) Delays at each centre}

The median delays at each centre are shown in Fig. 7. The median delay between first developing symptoms and first seeking care varies greatly between centres, from a high of 32 weeks in Mexico City to a low of less than one week in Nairobi. On the other hand, the delays between first seeking care (from someone acting in their professional capacity) and arrival at the mental health professional are very similar at all centres with the one exception of Ujung Pandang. The delays after seeing the first carer are remarkably short with medians of less than five weeks at almost all centres.

Substantial numbers of patients made direct access to the mental health services at three

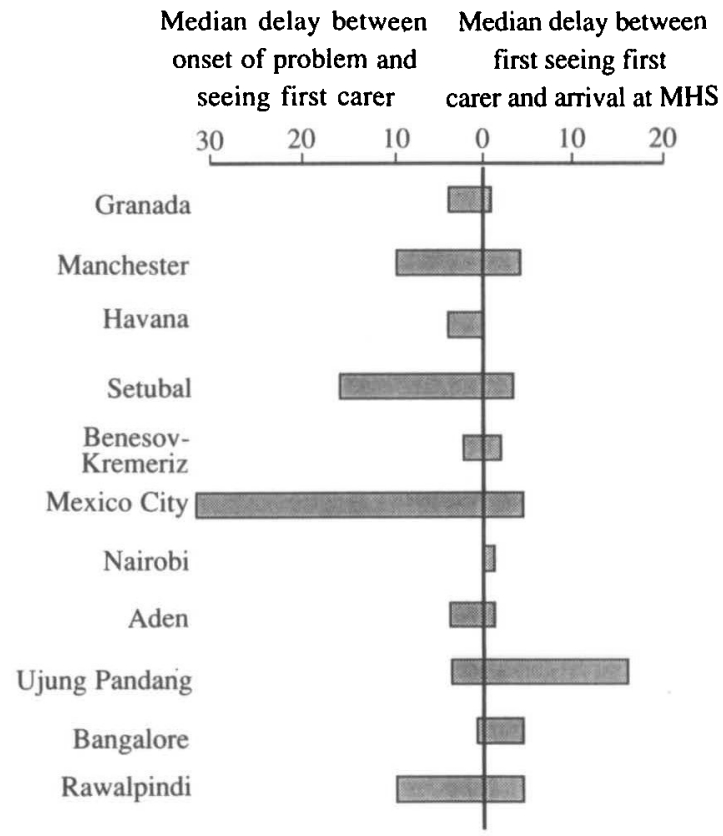

FIG. 7. Median delays in weeks between onset of problem and seeing first carer; and between seeing first carer and arrival at the mental health services (MHS).

centres: Mexico City, Bangalore and Rawalpindi. For each of these centres the total delay from onset of problem to arrival at the psychiatric services was compared for patients making direct access and those who had consulted previous carers. In Mexico City and Rawalpindi the delays were similar, but in Bangalore patients who went straight to the mental illness service had significantly shorter delays (median total delay of 12 weeks for direct access compared with 50 weeks for those with previous carers: $P<0.01$, Mann-Whitney $U$ test).

\section{(ii) Delays at the main carers}

The three main carers on the pathway to the psychiatric services are the primary care physician, the general hospital doctor and the native or religious healers. At least one of these carers appear on the pathways of over $80 \%$ of patients at each centre. The delays between being seen by these carers and arrival at the mental health services are shown in Table 2 . The seven centres at the top of the table are those with pathways on which the main carers are medical doctors. The delays following being seen by primary care 
Table 2. Median delays (weeks) at the main carers

\begin{tabular}{|c|c|c|c|c|c|c|c|}
\hline \multirow[b]{2}{*}{ Centre } & & & & \multicolumn{3}{|c|}{ Median delay after seeing carer } & \multirow[b]{2}{*}{$P \dagger$} \\
\hline & \multicolumn{3}{|c|}{ Count* } & $\begin{array}{l}\text { Primary } \\
\text { care } \\
\text { physician }\end{array}$ & $\begin{array}{c}\text { Hospital } \\
\text { doctor }\end{array}$ & $\begin{array}{l}\text { Native or } \\
\text { religious } \\
\text { healer }\end{array}$ & \\
\hline Granada & 178 & 59 & 0 & 1 & 0 & - & \\
\hline Manchester & 186 & 76 & 1 & $6 \cdot 5$ & 2 & 5 & \\
\hline Havana & 81 & 14 & 0 & 0 & $\mathbf{0}$ & - & \\
\hline Setubal & 183 & 37 & 4 & 4 & 2 & 8 & \\
\hline Benesov-Kromeriz & 46 & 24 & 0 & 3 & $2 \cdot 5$ & - & \\
\hline Mexico City & 93 & 33 & 5 & 4 & 4 & 22 & NS \\
\hline Nairobi & 12 & 109 & 5 & 5 & 1 & 48 & 0.07 \\
\hline Aden & 102 & 0 & 12 & 1 & - & 29 & $<0.01$ \\
\hline Ujung Pandang & 33 & 9 & 46 & 5 & 2 & 45 & $<0.05$ \\
\hline Bangalore & 27 & 25 & 13 & 48 & 36 & 52 & NS \\
\hline Rawalpindi & 34 & 22 & 19 & 8 & $2 \cdot 5$ & 6 & NS \\
\hline
\end{tabular}

* Count indicates the number of patients who saw primary care physicians, hospital doctors, and native/religious healers.

† Significance tested using Mann-Whitney $U$ test comparing delays after seeing primary care physician and native or religious healer.

Table 3. Median delays (weeks) between first seeking care and arrival at the mental health services for psychotic and not psychotic patients

\begin{tabular}{|c|c|c|c|c|c|c|c|}
\hline & \multirow[b]{2}{*}{ Centre } & \multirow{2}{*}{\multicolumn{2}{|c|}{ Count* }} & \multicolumn{2}{|c|}{ Median delay in weeks } & \multirow{2}{*}{$\begin{array}{c}P \dagger \\
\text { (Mann-Whitney } \\
U \text { test) }\end{array}$} & \multirow[b]{3}{*}{ (P) } \\
\hline & & & & Psychotic $\ddagger$ & $\begin{array}{c}\text { Not } \\
\text { psychotic§ }\end{array}$ & & \\
\hline & Granada & 20 & 213 & $\mathbf{0}$ & 1 & $<0.05$ & \\
\hline & Manchester & 46 & 189 & 2 & 6 & $<0-01$ & (P) \\
\hline & Havana & 4 & 74 & 1 & 0 & NS & \\
\hline & Setubal & 31 & 203 & 1 & 4 & $<0.01$ & (P) \\
\hline & Benesov-Kromeriz & 14 & 45 & 2 & 2 & NS & \\
\hline & Mexico City & 13 & 124 & 4 & 4 & NS & \\
\hline & Nairobi & 64 & 77 & 1 & 1 & $<0.01$ & (P) \\
\hline & Aden & 41 & 79 & 4 & 1 & $<0.01$ & $(\mathrm{~N})$ \\
\hline & Ujung Pandang & 48 & 19 & 22 & 14 & NS & \\
\hline & Bangalore & 4 & 75 & 7 & 4 & NS & \\
\hline & Rawalpindi & 17 & 70 & 6 & 2 & NS & \\
\hline
\end{tabular}

- Count indicates the number of patients who were diagnosed as psychotic, followed by the number who were not psychotic.

$\uparrow$ Significance value followed by $(P)$ indicates the psychotic patients had shorter delays; $(N)$ indicates that the not psychotic had shorter delays.

¥ Psychotic includes organic psychoses (including dementias, Korsakov syndrome and psychoses due to psychoactive substance abuse), schizophrenia, delusional disorders and mood disorders with psychotic symptoms.

$\S$ Not psychotic includes all other diagnoses (including not ill) with the exception of mental retardation which has been excluded from this table.

physicians are short in all these centres; and in three centres over half the patients go from first seeing their primary care physician to the mental health service within three weeks. The delays after seeing a hospital doctor are even shorter. The lower part of the table shows the centres where native or religious healers play an important part in the pathway diagram. In most of these centres the median delays after first seeing primary care physicians or hospital doctors are similar to the centres with more purely medical pathways. However, after seeing native healers there are longer delays in Nairobi, Aden and Ujung Pandang. These delays are significantly or near significantly longer than for the primary care physicians. This contrasts with Rawalpindi where the delay is comparable with that after seeing the primary care physician.

\section{(iii) Delays associated with diagnostic groups} To show the delays associated with different diagnostic groups we have simplified diagnosis 
into two broad groups: the psychotic, including organic psychoses, schizophrenia and mood disorders with psychotic features; and the notpsychotic, including all the remaining diagnoses except mental retardation which has been excluded from this calculation (see Table 3 ). The delays for psychotic patients are significantly shorter in Manchester, Granada, Setubal and Nairobi. In most other centres the delays for psychotic patients are short, but we have not been able to demonstrate that they are significantly shorter than for the not-psychotic patients.

\section{(iv) Main problems presented and their associated delays}

Overall, somatic problems are the most common initial presenting problem. Although it is frequently stated that somatic complaints are more often seen in third world countries, in this study there was no such tendency. Next are a group of five symptoms; anxiety, disturbed behaviour, depression, organic and psychotic problems each accounting for about $10 \%$ of initial problems. The percentages of patients at each centre presenting with three of these common problems; somatic, depression and anxiety related problems are shown in Table 4. There were other variations from the general pattern, for example, suicide attempt accounts for $11 \%$ of initial problems in Manchester but is rarely seen elsewhere. Drug problems account for $30 \%$ of presentations in Rawalpindi. In Bangalore over half presented with some form of epilepsy. In Nairobi and Ujung Pandang disturbed behaviour and psychotic problems were most common, together accounting for over $70 \%$ of first presentations.

By the time the patient arrives at the mental health professional the distribution of problems has changed. There is a marked drop in somatic presentations though they remain the most common type of problem. There is a corresponding rise in depressive presentations along with lesser increases in the percentage of anxietyrelated problems, disturbed behaviour, organic and alcohol or drug-related problems. This pattern is evident in all the centres.

Having confirmed the importance of somatic problems, it is interesting to look at the delays for somatic problems with other comparable presentations such as depression or anxiety- related problems (see Table 5). When the data from all the centres are combined the somatic problems have significantly longer delays. In Nairobi and Rawalpindi patients with somatic problems have longer delays. However, in Granada somatic problems have shorter delays than depression related problems.

Looking at the sample as a whole the commonest somatic presentations are headache and disturbed sleep, with headache appearing as a common presenting problem in all centres except Rawalpindi (see Table 6). Otherwise, no consistent pattern emerges, with five different somatic symptoms appearing most commonly. Sleep disturbance, weakness, genito-urinary symptoms, abdominal pain and back/chest pain are found in most centres. In contrast, fever is specific to Ujung Pandang and Rawalpindi; and loss of weight is only found with any frequency ( $9 \%$ of somatic problems) in BenesovKromeriz.

\section{(v) Delays and duration of journey to the mental health service}

In Table 7 the delays between first seeking care and arrival at psychiatric services are compared for patients with short and long durations of journey to the mental health professional. In seven centres patients with longer journeys tend to have longer median delays. This difference is significant in Manchester, Mexico City and Bangalore.

\section{Treatments received on the pathway}

In most of the centres the majority of patients say they have previously received some form of treatment for their presenting problem (see Table 8). Only in Nairobi do the majority of patients say they had received no previous treatment. In all centres, except Bangalore and Rawalpindi, between 25 and $56 \%$ of patients had received psychotropic medication usually in the form of a sedative or hypnotic. Treatment of physical illness is the most common form of previous treatment in Manchester, Mexico City, Ujung Pandang, Bangalore and Rawalpindi. Despite their pathways, which involve a substantial nonmedical component, patients seen in Ujung Pandang, Bangalore and Rawalpindi have received at least as much treatment of physical illness as those seen at the other centres. As might be expected psychotropic medication and 
Table 4. Percentage of patients presenting selected main problems to first carer and mental health professional

\begin{tabular}{|c|c|c|c|c|c|c|}
\hline \multirow[b]{2}{*}{ Centre } & \multicolumn{3}{|c|}{$\begin{array}{l}\text { Problem presented } \\
\text { to first carer }\end{array}$} & \multicolumn{3}{|c|}{$\begin{array}{l}\text { Problem presented to } \\
\text { mental health professional }\end{array}$} \\
\hline & \multicolumn{3}{|c|}{ Somatic Depression Anxiety } & \multicolumn{3}{|c|}{ Somatic Depression Anxiety } \\
\hline Granada & 30 & 15 & 21 & 20 & 16 & 31 \\
\hline Manchester & 18 & 14 & 18 & 9 & 20 & 18 \\
\hline Havana & 23 & 26 & 38 & 13 & 37 & 38 \\
\hline Setubal & 32 & 16 & 14 & 23 & 22 & 14 \\
\hline Benesov-Kromeriz & 57 & 12 & 2 & 35 & 13 & 2 \\
\hline Mexico City & 24 & 12 & 14 & 10 & 18 & 15 \\
\hline Nairobi & 18 & 3 & 2 & 14 & 4 & 2 \\
\hline Aden & 40 & 7 & 6 & 30 & 9 & 9 \\
\hline Ujung Pandang & 28 & 2 & 9 & 10 & 3 & 6 \\
\hline Bangalore & 19 & 13 & 0 & 14 & 17 & 1 \\
\hline Rawalpindi & 26 & 10 & 7 & 1 & 25 & 9 \\
\hline
\end{tabular}

Table 5. Median delays (weeks) between first seeking care and arrival at mental health services for somatic, depression and anxiety related problems

\begin{tabular}{|c|c|c|c|c|c|c|c|c|}
\hline \multirow[b]{2}{*}{ Centre } & & & & \multicolumn{3}{|c|}{ Median delay in weeks } & \multicolumn{2}{|c|}{ Significance $(P)$} \\
\hline & \multicolumn{3}{|c|}{ Count* } & Somatic & Depression & Anxiety & $\begin{array}{l}\text { Somatic } v \text {. } \\
\text { depression }\end{array}$ & $\begin{array}{c}\text { Somatic } v . \\
\text { anxiety }\end{array}$ \\
\hline Granada & 72 , & 36 & 50 & 1 & 2 & 1 & $<0.1$ & NS \\
\hline Manchester & 45 , & 36 , & 44 & 8 & 7 & 9 & NS & NS \\
\hline Havana & 22 , & 25 , & 36 & 0 & 0 & 0 & NS & NS \\
\hline Setubal & 80 , & 40 & 35 & 4 & 4 & 4 & NS & NS \\
\hline Benesov-Kromeriz & 34 & 7 & 1 & 5 & 2 & 1 & NS & NS \\
\hline Mexico City & 34 & 17 & 19 & 4 & 14 & $i$ & NS & NS \\
\hline Nairobi & 25 , & 4 & 3 & 24 & 1 & 5 & $<0.01$ & $<0.1$ \\
\hline Aden & 50 & 9 & 8 & 1 & 2 & 0 & NS & NS \\
\hline Ujung Pandang & 19 , & 1, & 6 & 14 & 52 & 3 & NS & NS \\
\hline Bangalore & 16 , & 11 & 0 & 25 & 0 & - & NS & - \\
\hline Rawalpindi & 23 & 9 & 6 & 8 & 1 & 1 & NS & $<0.05$ \\
\hline Combined & 416 & 194 & 205 & 4 & 2 & 2 & $<0.06$ & $<0.01$ \\
\hline
\end{tabular}

* Count indicates the number of patients presenting with somatic, depressive, and anxiety problems.

Table 6. Common somatic problems at each centre

\begin{tabular}{|c|c|c|}
\hline Centre & $\begin{array}{c}\text { Predominant } \\
\text { somatic problem }(\%)\end{array}$ & $\begin{array}{c}\text { Other common } \\
\text { somatic problems }(\%)\end{array}$ \\
\hline Granada & Headache (21) & $\begin{array}{l}\text { Dizziness (15) } \\
\text { Sleep disturbance (14) }\end{array}$ \\
\hline Manchester & Back/chest pain (13) & Headache (11) \\
\hline Havana & Sleep disturbance (27) & $\begin{array}{l}\text { Genito-urinary (18) } \\
\text { Headache (14) }\end{array}$ \\
\hline Setubal & Headache (21) & Sleep disturbance (20) \\
\hline Benesov-Kromeriz & $\begin{array}{l}\text { Dizziness (15) } \\
\text { Headache (15) }\end{array}$ & Sleep disturbance (12) \\
\hline Mexico City & Headache (29) & $\begin{array}{l}\text { Sleep disturbance }(20) \\
\text { Abdominal pain }(12)\end{array}$ \\
\hline Nairobi & Back/chest pain (32) & Headache (24) \\
\hline Aden & Sleep disturbance (52) & Headache (12) \\
\hline Ujung Pandang & Headache (26) & Fever (16) \\
\hline & Sleep disturbance (26) & Dizziness (16) \\
\hline Bangalore & Headache (38) & $\begin{array}{l}\text { Back/chest pain (13) } \\
\text { Dizziness (13) }\end{array}$ \\
\hline Rawalpindi & Abdominal pain (17) & $\begin{array}{l}\text { Weakness (13) } \\
\text { Fever (13) } \\
\text { Genito-urinary (13) }\end{array}$ \\
\hline
\end{tabular}


Table 7. Median delays (weeks) between first seeking care and arrival at the mental health services according to duration of journey to the mental health services

\begin{tabular}{|c|c|c|c|c|c|}
\hline \multirow[b]{2}{*}{ Centre } & & & \multicolumn{2}{|c|}{ Median delay in weeks } & \multirow{2}{*}{$\begin{array}{c}\text { Significance } \\
(P) \\
\text { (Mann-Whitney } \\
U \text { test) }\end{array}$} \\
\hline & \multicolumn{2}{|c|}{ Count* } & $\begin{array}{l}\text { Journey } \\
<1 \text { hour }\end{array}$ & $\begin{array}{l}\text { Journey } \\
>1 \text { hour }\end{array}$ & \\
\hline Granada & 211 & 23 & 1 & 1 & NS \\
\hline Manchester & 231 & 9 & 4 & 30 & $<0.05$ \\
\hline Havana & 93, & 2 & 0 & 1 & NS \\
\hline Setubal & 152 & 99 & 3 & 3 & NS \\
\hline Benesov-Kromeriz & 53 & 7 & 2 & 2 & NS \\
\hline Mexico City & 94 & 47 & 3 & 4 & $<0.05$ \\
\hline Ujung Pandang & 30 , & 38 & 8 & 36 & NS \\
\hline Bangalore & 32 & 53 & 0 & 12 & $<0.01$ \\
\hline Rawalpindi & 41 & 47 & 2 & 4 & $<0.1$ \\
\hline
\end{tabular}

- Count indicates the number of patients with journey times of less than one hour, followed by the number with journey times greater than one hour.

Table 8. Percentage of patients previously receiving various types of treatment before arrival at the mental health service

\begin{tabular}{|c|c|c|c|c|c|c|}
\hline Centre & $\begin{array}{l}\text { No previous } \\
\text { treatment }\end{array}$ & $\begin{array}{l}\text { Treatment } \\
\text { of physical } \\
\text { illness }\end{array}$ & Sedative & Antidepressant & Neuroleptic & $\begin{array}{l}\text { Nerve tablet } \\
\text { unspecified }\end{array}$ \\
\hline Granada & 39 & 14 & 26 & 4 & 1 & 0.5 \\
\hline Manchester & 32 & 34 & 14 & 10 & 1 & 6 \\
\hline Havana & 27 & 4 & 46 & 10 & 1 & 3 \\
\hline Setubal & 40 & 15 & 31 & 4 & 2 & 3 \\
\hline Benesov-Kromeriz & 27 & 25 & 28 & 12 & 5 & 2 \\
\hline Mexico City & 43 & 28 & 16 & 6 & 0 & 3 \\
\hline Nairobi & 68 & 6 & 8 & 4 & 10 & 6 \\
\hline Aden & 36 & 3 & 41 & 1 & 8 & 6 \\
\hline Ujung Pandang & 15 & 29 & 10 & 0 & 0 & 19 \\
\hline Bangalore & 42 & 29 & 4 & 1 & 0 & 2 \\
\hline Rawalpindi & 39 & 28 & 2 & 1 & 2 & 5 \\
\hline
\end{tabular}

Other previous treatments found in a few centres: native medicine, Ujung Pandang 52\%; practical aid, Ujung Pandang $28 \%$, Manchester $6 \%$; anticonvulsant, Bangalore $18 \%$; spiritual support, Rawalpindi $17 \%$, Ujung Pandang $12 \%$; counselling, Havana $12 \%$, Manchester $7 \%$, Ujung Pandang $6 \%$; ritual cure, Bangalore $12 \%$; alternative medicine, Bangalore $6 \%$.

treatment of physical illness account for most of the previous treatment received in the centres with predominantly medical pathways.

The treatments given by general practitioners (see Table 9) do appear to have some relationship with position in the table. In Ujung Pandang, Bangalore and Rawalpindi, patients rarely say they have received no treatment from their general practitioner: most said their general practitioner treated a physical illness. In all the other centres except Mexico City. the most common form of treatment given by general practitioners was sedative medication. Overall women were more often prescribed sedatives than men $(22 \%$ of women compared with $16 \%$ of men: $p<0.01, \chi^{2}$ test), this trend is seen in all centres except Nairobi and Aden but does not reach significance in any individual centre. Antidepressants were rarely prescribed by general practitioners in developing countries.

The treatment given by hospital doctors shows no clear pattern (see Table 10). In Nairobi, where most patients are seen by hospital doctors and then very quickly referred on to the mental health services, the hospital doctors rarely prescribe any psychiatric treatment themselves. While in Manchester the vast majority of patients say that their main treatment by hospital doctors was directed at a physical illness. In most other centres hospital doctors prescribe sedatives to a substantial percentage of patients.

The variation in treatments offered by native or religious healers reflects the heterogeneity of centres studied (see Table 11). Almost all the 
Table 9. Percentage* of patients receiving various main treatments given by general practitioners

\begin{tabular}{|c|c|c|c|c|c|c|}
\hline Centre & $\begin{array}{c}\text { No } \\
\text { treatment }\end{array}$ & $\begin{array}{l}\text { Treatment } \\
\text { of physical } \\
\text { illness }\end{array}$ & Sedative & Antidepressant & Neuroleptic & $\begin{array}{l}\text { Nerve tablet } \\
\text { unspecified }\end{array}$ \\
\hline Granada & 41 & 13 & 36 & 6 & 1 & 1 \\
\hline Manchester & 50 & 13 & 16 & 12 & 0.5 & 6 \\
\hline Havana & 22 & 4 & 50 & 11 & 1 & 4 \\
\hline Setubal & 32 & 17 & 39 & 5 & 1 & 4 \\
\hline Benesov-Kromeriz & 37 & 11 & 26 & 13 & 4 & 0 \\
\hline Mexico City & 35 & 36 & 17 & 4 & 0 & 2 \\
\hline Nairobi & 36 & 9 & 27 & 0 & 27 & 0 \\
\hline Aden & 29 & 3 & 47 & 1 & 9 & 6 \\
\hline Ujung Pandang & 3 & 55 & 15 & 0 & 0 & 27 \\
\hline Bangaloret & 7 & 56 & 7 & 0 & 0 & 7 \\
\hline Rawalpindi & 0 & 71 & 6 & 0 & 6 & 6 \\
\hline
\end{tabular}

* The percentage was calculated using the number of patients seen by general practitioners in each centre as the denominator.

$\dagger$ In Bangalore $22 \%$ were prescribed anticonvulsants.

Table 10. Percentage* of patients receiving various main treatments given by hospital doctor

\begin{tabular}{|c|c|c|c|c|c|c|}
\hline Centre & $\begin{array}{c}\text { No } \\
\text { treatment }\end{array}$ & $\begin{array}{l}\text { Treatment } \\
\text { of physical } \\
\text { illness }\end{array}$ & Sedative & Antidepressant & Neuroleptic & $\begin{array}{l}\text { Nerve tablet } \\
\text { unspecified }\end{array}$ \\
\hline Granada & 38 & 33 & 22 & 2 & 2 & 0 \\
\hline Manchester & 18 & 75 & 0 & 1 & 0 & 0 \\
\hline Havana & 64 & 14 & 21 & 0 & 0 & 0 \\
\hline Setubal & 22 & 19 & 39 & 0 & 8 & 3 \\
\hline Benesov-Kromeriz & 35 & 39 & 17 & 0 & 0 & 4 \\
\hline Mexico City & 28 & 13 & 19 & 13 & 0 & 0 \\
\hline Nairobi & 71 & 4 & 7 & 4 & 10 & 5 \\
\hline Ujung Pandang & 22 & 33 & 11 & 0 & 0 & 33 \\
\hline Bangalore ${ }^{-}$ & 16 & 40 & 4 & 0 & 0 & 0 \\
\hline Rawalpindi & 30 & 45 & 5 & 0 & 5 & 10 \\
\hline
\end{tabular}

* The percentage was calculated using the number of patients seen by hospital doctors in each centre as the denominator.

† In Bangalore $36 \%$ were prescribed anticonvulsants.

Table 11. Percentage* of patients receiving various main treatments given by native or religious healers

\begin{tabular}{lccccccc}
\hline \hline & $\begin{array}{c}\text { No } \\
\text { Centre }\end{array}$ & $\begin{array}{c}\text { Ritual } \\
\text { cure or } \\
\text { pilgrimage }\end{array}$ & $\begin{array}{c}\text { Spiritual } \\
\text { support } \\
\text { or prayer }\end{array}$ & $\begin{array}{c}\text { Native } \\
\text { medicine }\end{array}$ & $\begin{array}{c}\text { Herbal } \\
\text { medicine }\end{array}$ & $\begin{array}{c}\text { Practical } \\
\text { aid }\end{array}$ \\
\hline Aden & 33 & 33 & 0 & 8 & 25 & 0 & 0 \\
Ujung Pandang & 4 & 0 & 0 & 58 & 0 & 36 & 0 \\
Bangalore & 8 & 61 & 0 & 8 & 23 & 0 \\
Rawalpindi & 22 & 0 & 72 & 0 & 6 & 0 \\
\hline \hline
\end{tabular}

- The percentage was calculated using the number of patients seen by native healers in each centre as the denominator.

patients who saw native or religious healers in Ujung Pandang and Bangalore say they received some form of treatment from them. In Ujung Pandang this is usually native medicine, but in over a third it is practical help; a main treatment rarely found in any other setting. In Bangalore and Aden a ritual cure is most common followed by herbal remedies, while in Rawalpindi prayer or other spiritual forms of support are common.

\section{DISCUSSION}

The Pathway Study can be carried out with minimal resources and completed within a calendar month. It is a simple and inexpensive method of obtaining information about ways in which patients with psychological problems obtain help. This paper presents data, gathered retrospectively, about patients who are referred 
on to psychiatric care. It gives no account of those who do not come into contact with the mental health services. Therefore, it tends to emphasize the importance of medical carers, who are perhaps more likely than non-medical carers to refer patients on to their medical colleagues in psychiatry. Other studies starting from other sources of care will be necessary to complete the mapping of care providers in the communities studies. A second limitation relevant to some centres is that the method depends on the willingness of patients to acknowledge their previous sources of care. In some settings, where native healers now have low status, patients may be reluctant to admit that they have sought this type of care.

Table 1 provides suggestive evidence that services with more resources are associated with female preponderance of new cases, while those with fewer staff tend to have a male preponderance: only Bangalore seems not to obey this rule, with an equal sex incidence despite having relatively few staff.

It has been shown that services with more psychiatrists are associated with predominantly medical referral pathways: perhaps reflecting a tendency for societies with more psychiatrists to have more general practitioners and physicians as well. The centre with the largest percentage of native healers involved in the pathway is Ujung Pandang: it is clear that a centre that has been prepared to develop its relationships with indigenous healers has been able to provide mental illness services to those who have initially sought help from non-medical sources.

There is no evidence that having more staff results in less delay in obtaining care. The evidence that allowing direct referrals to the service results in less delay in obtaining care is mixed: in Mexico City and Rawalpindi patients making direct access to the service had similar total delays to those arriving after seeing other carers, but in Bangalore direct access is associated with shorter total delays. However, we have presented evidence that those passing through native healers experience longer delays: and we have also seen that native healers are often associated with recursive pathways meaning that patients are perhaps only referred to the mental health services as a last resort.

It had been expected that shorter delays would have been experienced by those living nearer to the service, and by those presenting with psychotic disorders. These effects were present, but only in a minority of the services. However, where the former effects were present decentralizing psychiatric services and providing local access might diminish some delays.

Longer delays occurred with those presenting with somatic symptoms - but this is an almost inevitable finding, since many such patients require physical investigations before they are referred to the mental illness services. However, we suspect that many such patients could in fact have been referred earlier in the course of their illness. As Goldberg \& Bridges (1988) pointed out, somatic symptoms are just as common as presenting symptoms of mental disorder in developed countries as they are in the rest of the world.

However, in general the delays between first seeking care and being referred to the mental illness services are remarkably short, so that if other areas for secondary prevention are to be sought it would be in those centres where there is an unusually long delay between developing symptoms and first seeking care: this would lead one into more detailed investigations in Mexico City, Setubal and Manchester.

The study has, therefore, succeeded in documenting important points in the referral pathways in various centres, although the methodology used in the study does not allow us to know those points in the pathway where there are many patients who might have been referred, but were not. For example, Huxley et al.'s (1989) work in Manchester shows that the prevalence of psychiatric disorder in social work clients is about $50 \%$ at inception, and $25 \% 12$ months later; yet social workers feature in the pathways of only $3 \%$ of Manchester patients. It would therefore be useful to assess the recognition and management of psychiatric disorders among the clients of groups of carers like social workers who do not appear as often as expected.

The study has suggested possible areas for preventive action in hastening referrals in those attending native healers, and has focused attention on those presenting in general medical clinics with somatic symptoms. Although somatic symptoms are the commonest initial presentation, patients with these problems do seem to be referred on more slowly in some 
centres. This suggests an indication for training specifically targeted at the recognition of psychiatric disorders presenting with somatic symptoms.

The proportion of patients with depressive disorders at each centre was broadly comparable, yet in the developing world general practitioners had rarely prescribed antidepressant medication. This may suggest an indication for training in the recognition and management of depressive disorders for general practitioners in these centres.

The methodology reported here is quick to administer and requires minimal additional resources. Yet it provides valuable information about the route followed by patients seeking care for psychiatric disorders, and helps focus on potential sources of delay in care seeking or referral. Other centres wishing to apply this method of self study can obtain copies of the protocol and manuals from the Mental Health Division, World Health Organization, Geneva.

The authors would like to thank the many research workers and clinicians who organized or participated in the fieldwork at each centre, without their interest and cooperation the study could not have been completed so efficiently: R. Ramos, J. Pico, M. Leon and T. Hernandez in Cuba; C. Skoda, J. Kulhanek and J. Eim in Czechoslovakia; S. M. Channabasavanna, G. N. Narayana Reddy, R. Srinivasa Murthy, Sundar Moili, K. V. Kishore Kumar, G. S.
Uday Kumar, K. R. Subramanya, S. B. Hirematt, H. P. Chinnaya and Ms Puttamma in India; Ngadiono Hastering and Mursyid Ishak in Indonesia; E. A. P. Muluka and Miriam Lukwago in Kenya G. Heredia, I. Cervantes and C. Varela in Mexico; A. Guimaraes, D. Osorio, F. de Freitas, G. Wilson, H. R. da Silva, J. Sennfelt, J. S. Martins, M. A. Cardoso and M. Neves in Portugal; S. Bakhsh, Q. Nazar and S. Afghan in Pakistan; S. C. Garg, A. Alyahri, Z. Munarak and all professional staff of the NP Hospital, Aden in the People's Democratic Republic of Yemen; J. Fernandez and C. Rosales in Spain; and Susan Halliday, Samantha Warner and Rebekah Williams in the United Kingdom. Christine Russell has assisted in the coordination of the study from Geneva. The fieldwork in Manchester was funded by the Mental Health Research Foundation.

\section{REFERENCES}

Goldberg, D. P. \& Bridges, K. (1988). Somatic presentations of psychiatric illness in primary care settings. Journal of Psychosomatic Research 32, 137-144.

Goldberg, D. P. \& Huxley, P. (1980). Mental Illness in the Community: The Pathway to Psychiatric Care. Tavistock: London.

Harding, T. W., De Arango, M. V., Baltazar, J., Climent, C. E., Ibrahim, H. H. A., Ladrido-Ignacio, L., Srinivasa Murthy, R. \& Wig, N. N. (1980). Mental disorders in primary health care; a study of their frequency and diagnosis in four developing countries. Psychological Medicine 10, 231-241.

Huxley, P., Raval, H., Korer, J. \& Jacob, C. (1989). Psychiatric morbidity in the clients of social workers: clinical outcome. Psychological Medicine 19, 189-197.

Sartorius, N. \& Harding, T. W. (1983). WHO collaborative study on strategies for extending mental health care, $I$ : the genesis of the study. American Journal of Psychiatry 140, 1470-1473.

SPSS (1986). SPSS-X Statistical Package for the Social Sciences. SPSS Inc: Chicago. 